\title{
Goods logistics in the city centre of Brno
}

\author{
M. Pokorná \& K. Nedvědová \\ Transport Department, Brno City Municipality, Czech Republic
}

\begin{abstract}
The topic of this article is about goods logistics in the city centre of Brno. The city's logistic concept should mitigate the negative impact of urban freight transportation without penalizing the activities in the city of Brno such as economic, social or cultural activities. Freight and business traffic in urban areas is a very important topic due to the essential economic and societal needs. The gaining of experience in city freight and business traffic management will therefore contribute to the European objectives, especially in energy savings end emission reductions. City logistics have to respect the need of the city to include its solution into the framework of the urbanistic concept of development or also environmental issues of the city including safety of traffic. City logistics do not concern only freight transport, it is necessary to take into account all the movements of the persons in the city area, which are needed for the operation of the enterprises, services and entrepreneurial locations, i.e. "official" private transport. Within the analytic part the available information is gained on the current state of the supply system in Brno, finding the location of the largest targets for supply transport and the structure of supply cars in the individual zones. The necessary changes in the supply system in Brno (especially in the centre area of the town) will be solved in the proposal part of this article. The locations of the logistics centre or more logistics centres in the context of their connection to the transport infrastructure will be suggested. The efficiency and profitability of operations of logistics relationships will also be assessed. The demand for the use of logistic centres from retailers and small traders will also be solved as well as the acceptability of locating logistic operations and their use by customers.
\end{abstract}

Keywords: city logistics, distribution centre, freight transport, Brno. 


\section{Introduction}

The importance of logistics supply to cities is increasing. Specific requirements for transport services have given rise to the term city logistics, which refers to the use of logistics in densely populated areas. In many urban areas city logistic plays an important role.

City logistics have already been practically applied for a few decades, not only in Western European cities, in order to ensure the necessary transport service business units in the centre with the lowest driving performance of service vehicles.

According to Benjelloun et al. [1], the concept of city logistics has emerged as an approach to mitigate the negative impact of urban freight transportation without penalizing the city's many economic, social, administrative, cultural, touristic, and other activities.

The city logistics system is important for the reason of achievement better quality of life. This fact is well recognized by local recognized by local authorities and therefore is often included in strategic plans or sustainable urban mobility plans [2].

An efficient city logistics system has a significant role in the competitiveness of an urban area and it is an important part of the urban economic development. The competitiveness in logistics can improve the regional distribution of productive forces, improve the investment climate and thus improve the overall quality of urban economy, improve and enhance the competitiveness of the city $[3,4]$.

Taniguchi et al. [5] define city logistics as "the process for totally optimizing the logistics and transport activities by private companies in urban areas while considering the traffic environment, the traffic congestion and energy consumption within the framework of a market economy." The city centre of Brno suffers under the steadily increasing traffic caused by supply of shops and business premises, as well as by transport of large shipments.

Because of the involvement the city of Brno in project CIVITAS 2MOVE2 it was possible to create the study on City Logistics that was carried out by CDV [6] for the assessment of the need of change in the approach of the city management particularly in creating conditions for the mobility of goods in the city centre.

\subsection{Selected area for city logistics research in Brno}

The study on City logistics in Brno was held within the project CIVITAS 2MOVE2. This project is concerned with the improvement of urban mobility by advancing or creating sustainable, energy-efficient urban transport systems in the participating European cities.

In order to address the study "City Logistics in Brno" an area in the centre of Brno (the historical part) was defined, with a high concentration of stores. The monitored area is the historical centre of Brno with its surroundings; de-facto defined by small city circuit. The area has an area of about 158 hectares with a 
population of about 11,000 and is defined by the following streets and squares: Husova - Nádražní - Benešova - Koliště - Moravian Square - Žerotínovo Square - Comenius Square. There is a ban in this area on all motor vehicles and vehicles that weigh more than 3.5 tons, i.e. the vehicles cannot enter without historical permission from the drive in MMB.

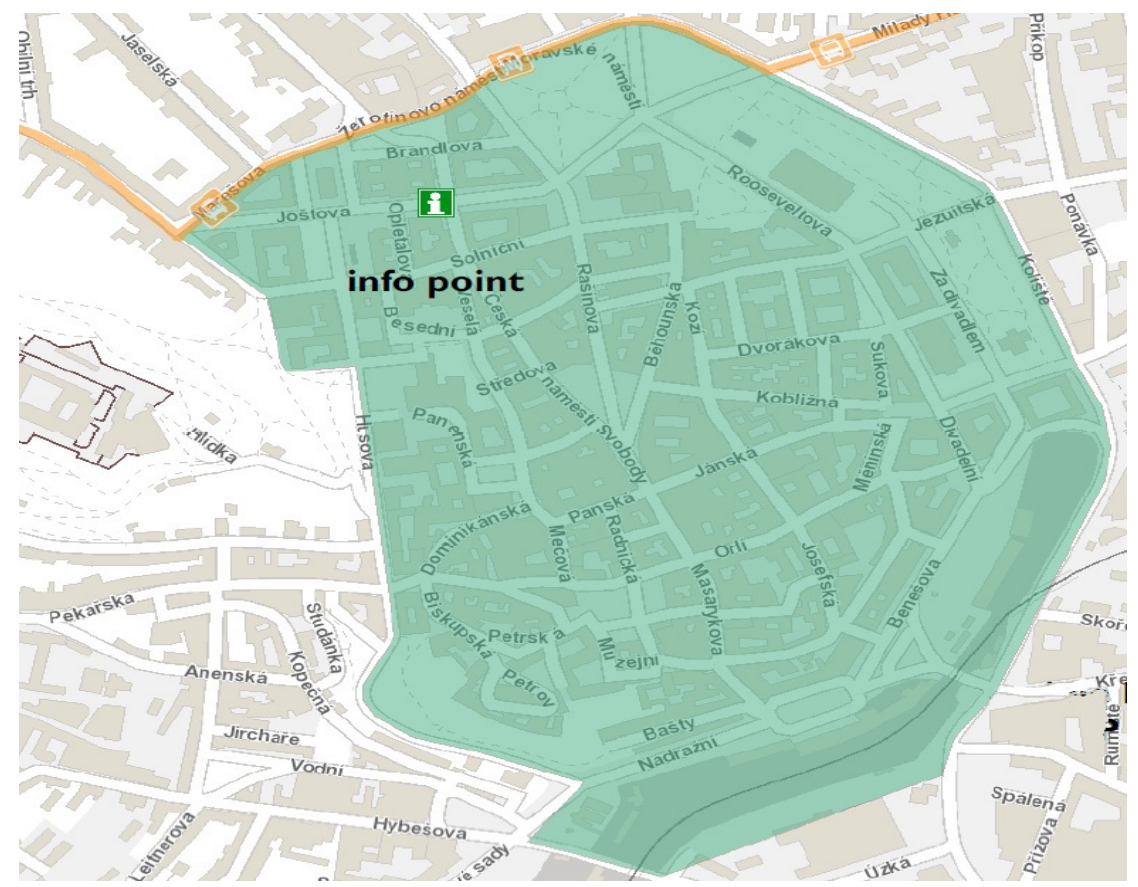

Figure 1: Location of research in city centre of Brno.

\section{Methodology of city logistic research in Brno}

Within the study "City Logistics of Brno" a questionnaire was designed to fill/define basic requirements for the analytical phase of the study. For these purposes, areas of the historical centre were defined, which are characterized by a very high number of retail units and a geographic area that should be addressed by using a city logistics from the perspective of representatives of the city of Brno. One of the main goals is to relieve the traffic from the traffic load caused by supply.

The questionnaire survey was conducted during May 2013. A total of 682 retail units were addressed in the field. The total number of returning questionnaires was 504 completed questionnaires, representing a return of $74 \%$. The main objective of the analytical part was to determine the following parameters of monitored area and carried out in the supply process: 
- Types of stores, variety of goods;

- Frequency of supply;

- The volume of generated traffic;

- Type of supply vehicles;

- Information about the course of a supply shutdown;

- Existing supply problems;

- Opinions of store operators at MDC.

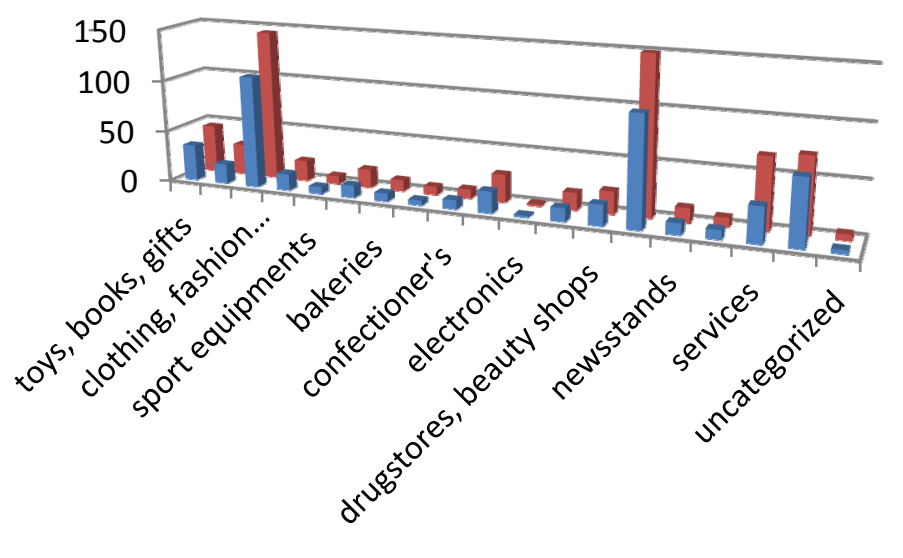

number of returned questionnaires

Figure 2: Categories of stores in the area.

\subsection{Evaluation of questionnaires}

From Figure 2 it is evident that there is some potential that would allow to consolidate the shipments directed into the area. It will be mainly the following categories of goods:

- Toys, books, gifts

- Clothes, fashion accessories

- Shoes

- $\quad$ Sport equipments and services

With regard to the possible use of city logistics applications that use traffic control with the help of so-called time windows, was one part of the survey focused on the number of stores that are open in given hours. Due to this survey it is possible to confront the proposals for the creation these time windows with current state in the area and the proposed measures are not in direct contradiction with retail activities in the monitored area.

On the following graphs, there are obvious features of retail network, when on weekdays, there is distinct sharp increase in the number of open stores between 8:00 and 10:00 and on the contrary, there is the steep decline during the 
time between 18:00 and 20:00. At the weekend, there is the noticeable decrease the number of open stores, with the exception of Saturday morning. It is can be seen, the decrease in the number of open stores is noticeably more balanced. This state is characterized by the composition of the stores when the stores focused on mainly the restaurants and cafés on weekends and holidays.

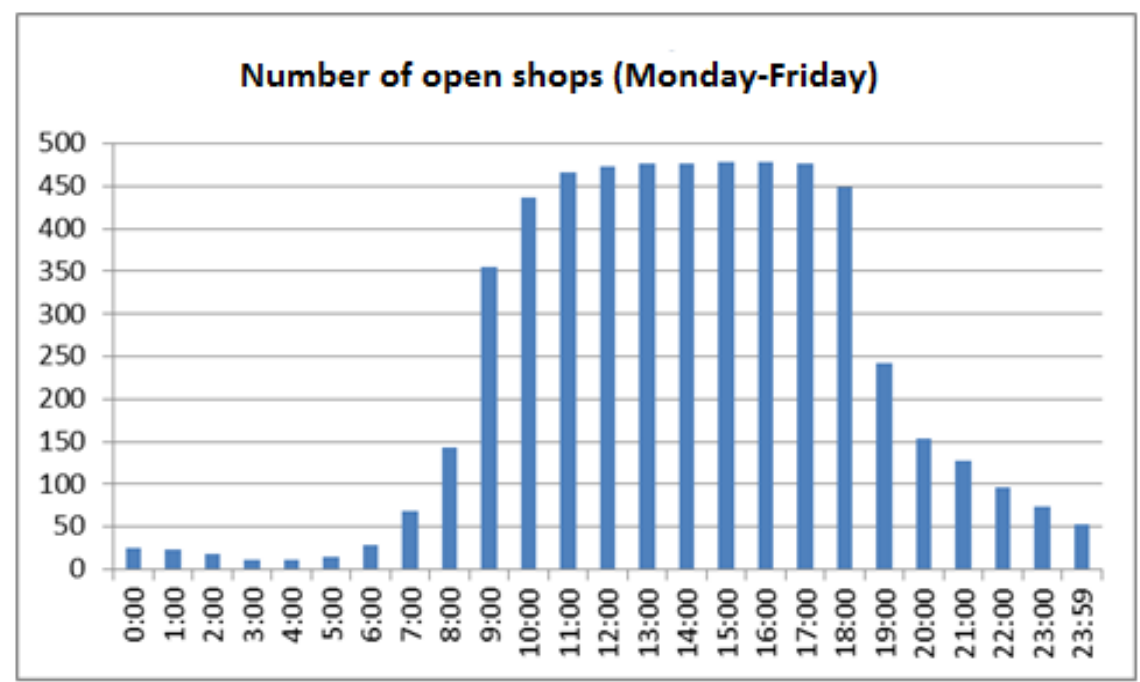

Figure 3: The number of open shops from Monday to Friday.

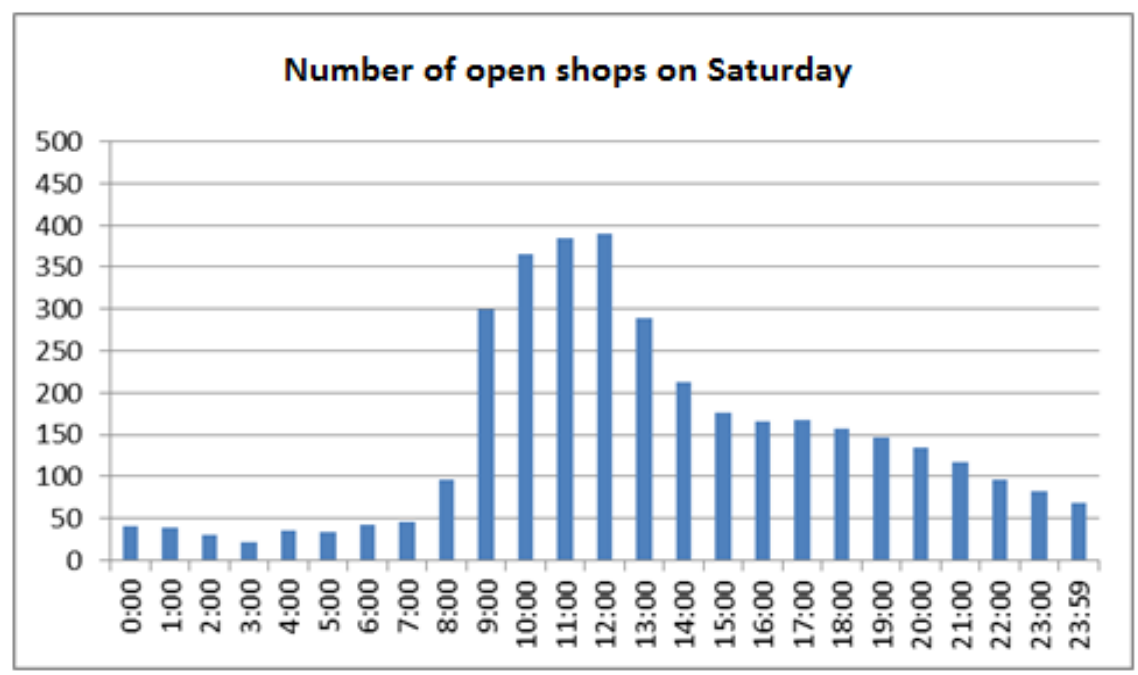

Figure 4: The number of open shops on a Saturday. 
The first monitored characteristic was the kind of supply vehicles. It was studied the category of vehicles that are used for the supply of the trade. The overview distribution presents the following table. Retailers could vote for more than one vehicle category in their answers that are most involved in the supply and therefore the sum of individual vehicles assigned to a given categories gives a sum greater than the number of returned questionnaires (that is 504).

Table 1: Categories of vehicles involved in the supplying.

\begin{tabular}{|l|r|}
\hline \multicolumn{2}{|c|}{ Category of cars } \\
\hline Passenger cars & 279 \\
Van & 372 \\
Lorry $(3,5-12 t)$ & 69 \\
Lorry (over 12 t) & 2 \\
No answer & 2 \\
\hline
\end{tabular}

From Table 1 it is obvious a high proportion of passenger cars involved in the supply of business units. This proportion is approximately twice that made by shares of passenger cars involved in the supply of previous surveys carried for example in Chomutov and Liberec in 2009.

This case can be explained by two facts. The first of them is the increasing proportion of SUV and MPV, which can be used for the supply (offers sufficient space for the transport of goods). This increase in the proportion of these categories of supply vehicles may just reflect the increasing proportion of these vehicle categories on sale in the automotive industry, particularly in Europe.

The second explanation provides the existing restrictions in the area where the entry of vehicles is restricted by weight (not above 3.5 tonnes). The traders that are using the category vehicles less than 3.5 tonnes with the entrance permission into this area (mainly passenger vehicles) need to adapt this fact.

Besides the actual volume of traffic associated with the supply, it is desirable also knowledge of its distribution in time. Then it can be considered the suitable city logistics applications in relation to their distribution during the day such as the access restrictions in these hours, etc. for the reflection of the current state. Because of a view of city logistics is not the suppression of retail trade in given areas, but the process of optimization of the supply area.

From Figure 5 it is clear that the most of the supply is between 8:00 a.m. to 10:00 a.m. In the general concept of city logistics can be the abovementioned dividing described graphically in terms of relationships between the different groups. 


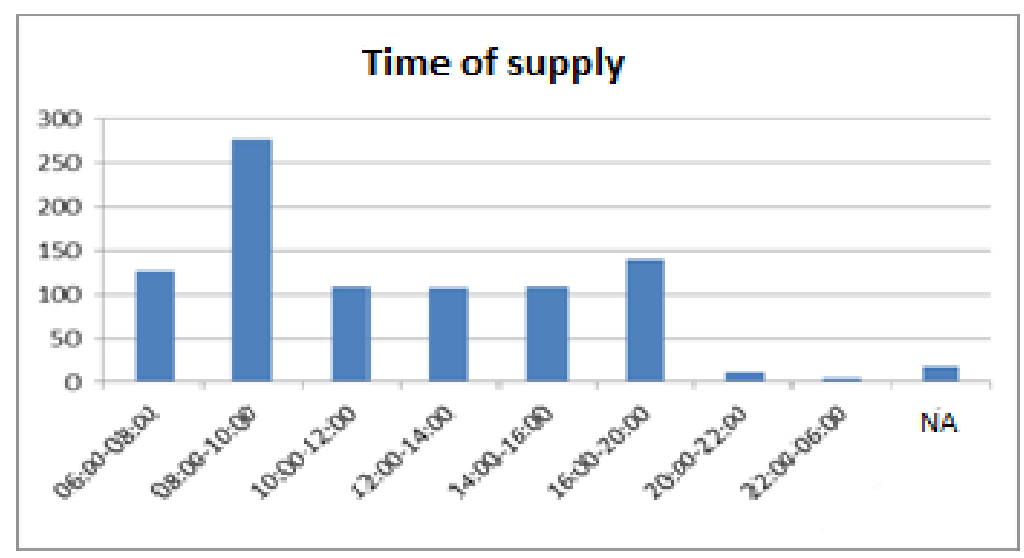

Figure 5: The time of supply.

\subsection{Locality for application of city logistics}

The space restrictions in the city centre limit the capacity for the traffic, so in particular for the static traffic. Due to this reason the traffic in this part of the city is regulated by organizational, technical and pricing measures. However, the limits of these measures are indicated by the experiences from traffic. In view of the change in the product structures of shops in the city centre it is seen an absolute decrease in the proportion of journeys heavy and light goods vehicles in terms of supply and transfer part of the supply via passenger vehicles with a tonnage of up to 3.5 tonnes. From the perspective of regulation of this transport is not possible to segment the mobility of goods in relation to the mobility of persons. For this reason it is necessary to solve freight and individual automobile transport to increasing the effectiveness of traffic regulation in the city centre.

At the same time there is the merging of mobility people and goods via individual automobile transport which result in increase the need for parking spaces. This is applied for the supply of store network in city centre, as well as for the majority of services for residents. Generally the aforementioned facts have these negative effects:

- Economic (congestion, low efficiency, waste of funds);

- Environmental (emissions of pollutants);

- Social (factors influencing the quality of life of residents).

The regulation of traffic is applied in the historical part of city centre in the current time. The target zone for application of city logistics is therefore the only city district in Brno. On the basis of international experience, it is possible to establish the following requirements for the distribution zone of city logistics project:

- Dislocations on the outskirts of the city with direct connection to the centre;

- Land size approximately $4000 \mathrm{~m}^{2}$ and capacity to allow the development in the next 25 years; 
- Transport connection to the city road network and nationwide core network of motorways, rail connections, access to the international airport;

- Accessibility to business districts outside the centre by high capacity road connection;

- The master plan has to allow traffic consuming activity - distribution, storage and maintenance (truckcentrum).

\section{Locality for application of city logistics}

With reference to the questionnaire survey it can be stated that in the area there is currently sufficient potential for using the services of city distribution centre by retailers. With the use of this premise there are defined two default options for consideration.

These two options are different especially in the number of involved stores, especially in the first years. These are:

- Option I - pessimistic estimate of the involved stores,

- Option II - an optimistic estimate of the participating stores.

For Option I the upper limit of 100 stores was chosen, and for Option II, 205 participating business units were selected.

Table 2: Evaluation of the scenarios.

\begin{tabular}{|l|r|r|}
\hline & I - pessimistic version & II - optimistic version \\
\hline Vehicle kilometre reduction & $-59,375$ & $-122,312$ \\
\hline Number of involved stores & 100 & 206 \\
\hline Size of MDC & 650 & 650 \\
\hline Number of trip to MDC & 2600 & 5356 \\
\hline
\end{tabular}

Within the CBA analysis there are evaluated the costs and benefits for all identified groups participating on this concept, simply said there is financially evaluated the benefits and costs for the whole society. In accordance with the division of participants of city logistics concept there are indentified the cost and benefits for these groups:

- Local governments;

- Carriers;

- Traders/retailers.

The expression of the benefits and costs that are considered in the context of CBA analysis is shown in Table 3. 
Table 3: Costs and benefits.

\begin{tabular}{|c|c|c|c|}
\hline & $\begin{array}{l}\text { Local } \\
\text { governments }\end{array}$ & Carriers & Traders/Retailers \\
\hline Costs & $\begin{array}{l}\text { Ensure the } \\
\text { operation of } \\
\text { MDC } \\
\text { Supporting } \\
\text { transport } \\
\text { measure }\end{array}$ & $\begin{array}{l}\text { Possible higher cost of } \\
\text { travel to centre via MDC } \\
\text { (depends) } \\
\text { Possible costs of goods } \\
\text { distribution via MDC } \\
\text { (depends) }\end{array}$ & $\begin{array}{l}\text { Cost of delivery (see } \\
\text { the approach adopted } \\
\text { in CBA) }\end{array}$ \\
\hline $\begin{array}{l}\text { Benefit } \\
\mathrm{s}\end{array}$ & $\begin{array}{l}\text { Improvement of } \\
\text { traffic situation } \\
\text { in the city } \\
\text { centre } \\
\text { Improvement of } \\
\text { environment } \\
\text { Increase the } \\
\text { attractiveness of } \\
\text { the city centre }\end{array}$ & $\begin{array}{l}\text { Reducing the cost of travel } \\
\text { to centre via MDC in } \mathrm{km} \\
\text { (depends) } \\
\text { Reducing the time spent in } \\
\text { city centre due to supply } \\
\text { Possibility of increasing } \\
\text { the loading area of car for } \\
\text { the region }\end{array}$ & $\begin{array}{l}\text { Reducing the time of } \\
\text { receipt of goods } \\
\text { (fewer suppliers - the } \\
\text { saved time vs. } \\
\text { delivery fee) }\end{array}$ \\
\hline
\end{tabular}

\section{The proposal of city logistics measure for the city of Brno}

The authors of the study recommend to the authorities of the city of Brno to implement the project of City Logistics. The foreign experiences confirm the knowledge that the implementation these projects are very long-term process within the horizon of 10 years and more. The foreign experiences show also that the concept of city distribution centre cannot be in most cases self-financed, see e.g. Van Roojien and Quak [7].

It is necessary to participate in the using of this concept the maximum possible number of traders and in the early phase count with a certain level of funding of its operations.

From this reason it is suggested to split the project of city logistics into 5 years and 4 phases.

- Phase 0 - Elaboration of feasibility study and establishment of platform BDP. The output of this phase should be the approval of the project (budget, schedule, to ensure the implementation of documentation, etc.).

It is suggested to implement the preparatory phase in 2013-2014. There is also a suggestion to divide the implementation process into three phases as follows:

- Phase 1 (2014-2015) - reserved place for supplying,

- Phase 2 (2015-2016) - support of ITS, involvement of DIC Brno,

- Phase 3 (2016-2018) - implementation of the City Distribution Centre. 


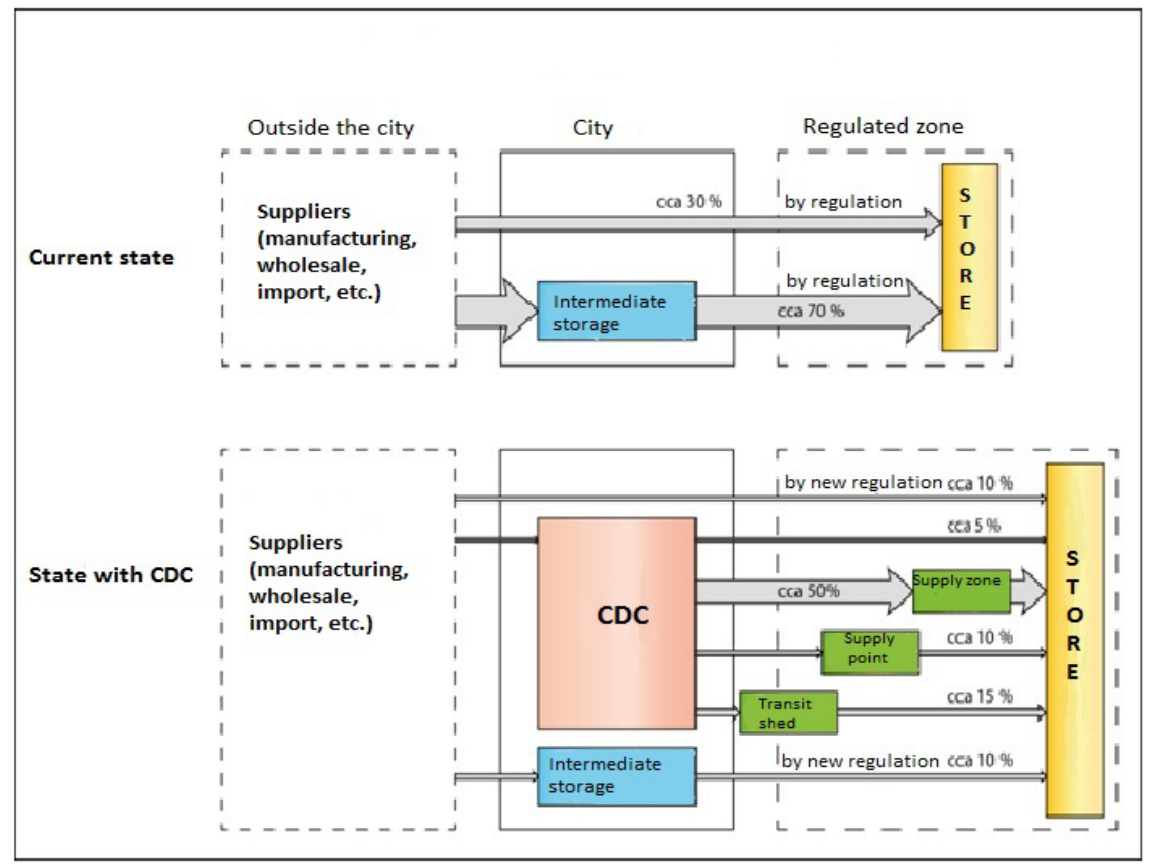

Figure 6: The schema of changes in the logistics chain.

The concept of city distribution centre will influence the activities of many organizations in the city and outside. For these reasons, it is necessary to start discuss this concept before its implementation with a broad group of stakeholders. These are such businessmen having their stores in a given area, carriers of goods, logistics companies, local inhabitants, local authorities, but also the potential operator of this concept. Implementation of this concept is long-term process that has to be thoroughly planned. The city distribution centre can or rather have to be supported by other measures that change the supply conditions in the city. In considering the success of the concept of city distribution centre it is necessary to know precisely the conditions under which the city distribution centre exist or for what purpose it is operated.

From the viewpoint of logistics, then the implementation of the urban distribution centre means the addition of another segment in the chain of distribution of goods. From the economic perspective then other costs connected with transhipment, short-term storage, loading of goods on the vehicle and the actual costs to delivery of goods. The administration and information exchange also increase the cost of transporting goods. On the other side, this concept provides an opportunity to regrouping, consolidation of shipments, maximal use of cargo space vehicles and the overall optimization of the logistics chain ensured by cooperation between companies. All these aspects need to considered and we need to set concrete measurable targets. Based on these aspects it will be possible to evaluate this concept and make decisions about its continuance. 


\section{Conclusions}

About the suitability or the unsuitability of city distribution centre is always difficult decide in advance. In relation to the city of Brno it can be stated that in the area that it should be served, there are plenty of potential trades that could use the services of the city logistics' concept. In addition, there is a development area for the creation of a logistics area that could be part of a city distribution centre. The logistics area is connected to the capacitive road, similar to how the railway infrastructure is available.

On the other hand there is the willingness of retailers to participate in this concept and other aspects of market economy. The market economy creates such conditions that in the majority of cases will find the necessary balance between suppliers and customers so that both groups can succeed in a competitive environment of its kind business.

About the success that means the suitability for a particular city, so it is decided in the real operation. The City of Brno fulfils all the attributes that might indicate its possible future operation. Firstly, it is necessary to define the specific objectives to be met, or measurable aspects according to which it will be possible to decide the success or failure of the operation of the city distribution centre. It is necessary to choose a consistent communication strategy representing this concept and last but not currently support the functioning of the concept by other measures in the defined area of the city of Brno.

\section{References}

[1] Benjelloun, A., Crainic, G.T. \& Bigras, Y., Towards a taxonomy of City Logistics projects. Procedia Social and Behavioral Sciences. 2(3), pp. 6217-6228, 2010.

[2] Witkowski, J. \& Kiba-Janiak, M., Correlation between city logistics and quality of life as an assumption for referential model. Procedia Social and Behavioral Sciences. 39, pp. 568-581, 2012.

[3] Russo, F. \& Comi, A., A classification of city logistics measures and connected impacts. Procedia Social and Behavioral Sciences. 2(3), pp. 6355-6365, 2010.

[4] Han, M., Hen, C., \& Han, Y. pp. 1259-1264, 2013. Evaluation of Western China city logistics competitiveness. International Conference on Industrial Engineering and Management Science-2013, eds. X. Chen, Y. M. Sun, pp. 1259-1264, 2013.

[5] Taniguchi, E., Thompson, R. G. \& Yamada, T. Modelling city logistics. In E. Taniguchi, \& R. G. Thompson (Eds.), City Logistics I: 1st International conference on city logistics, pp. 3-37, 1999.

[6] CDV, V.V.I., Intens Corporation S.R.O. \& Asociace financování infrastruktury pro mobilitu o.s., CITY Logistika města Brna, pp. 132, srpen 2013.

[7] Van Rooijen, T. \& Quak, H., Local impacts of a new urban consolidation centre - the case of Binnenstadtservice.nl. Procedia Social and Behavioral Sciences. 2(3), pp. 5967-5979, 2010. 